\title{
Processos Formativos em Teatro Musical no Ensino Técnico em Artes Cênicas: um relato de experiência multiperceptivo
}

\author{
Fidelcino Neves Reis \\ Fundação de Apoio à Escola Técnica do Rio de Janeiro - FAETEC, Rio de Janeiro/RJ, Brasil \\ E-mail: fidelreis@hotmail.com
}

\section{Resumo}

Baseado no relato de experiência do autor, o presente artigo busca investigar algumas estratégias metodológicas elaboradas para atender a formação técnica e também profissional de alunos no gênero Teatro Musical. Nesse sentido, o conceito de gesto multiperceptivo, o qual busca integrar a preparação corporal com o trabalho vocal de modo consciente, foi considerado uma ferramenta importante para o desenvolvimento das metodologias apresentadas ao longo desse texto. O campo da pesquisa nos desafiou a refletir sobre o desenvolvimento de um trabalho de exploração sensorial, através de uma abordagem somática, que permitisse ao aluno-ator experimentar as múltiplas artes que dialogam com o espetáculo teatral, estimulando-o a desempenhar várias funções em um musical.
Based on the author's experience report, this article seeks to investigate some methodological strategies designed to meet the technical and also professional training of students in the Musical Theater genre. In this sense, the concept of multiperceptual gesture, which seeks to integrate body preparation with vocal work in a conscious way, was considered an important tool for the development of the methodologies presented throughout this text. The research field challenged us to reflect on certain issues, for example, the development of sensory exploration work, through a somatic approach, which would allow the student-actor to experience the multiple arts that dialogue with the theatrical spectacle, stimulating the student-actor to perform various functions in a musical. 


\section{Introdução}

Em quase trinta e dois anos dedicados às artes, e vinte anos ensinando as novas gerações no fazer teatral, tenho observado o quanto a figura do ator que canta e dança desperta o interesse dos alunos. Por esta razão, defendo uma formação mais qualificada para aqueles que desejam atuar em musicais. Ao observarmos o número expressivo de espetáculos em cartaz e de público, ficam evidenciados tanto o crescimento quanto a popularização alcançados pelo Teatro Musical no Brasil e é possível perceber como esse gênero pode se tornar uma ferramenta para os professores de artes cênicas desse país.

Em um espetáculo musical, tanto os recursos de voz quanto os de corpo podem ser explorados com simplicidade e naturalidade, possibilitando um melhor desempenho do ator. Mas, para que isto ocorra, proponho pela minha prática que os alunos de teatro estudem esses elementos de maneira lúdica, a fim de que se desenvolvam e possam promover uma performance com qualidade.

Em artigo1, Tânia Brandão destaca que "o novo musical busca desenvolver uma forma cênica em sintonia com a vida atual - uma vida em que a intensidade do corpo é um valor de primeira grandeza" (BRANDÃO, 2018, n.p). A autora acrescenta que, mesmo quando se fala do passado, "o teatro descobriu que encenar não é apenas fazer fluir a voz, como se o físico fosse uma estaca alto-falante" (BRANDÃO, 2018, n.p).

Essa afirmação nos faz refletir a respeito de que, atualmente, um curso de Teatro Musical deve propor atividades para qualificar um aluno-ator para se tornar um artista que possa atuar cantando e dançando. O aluno precisa ter a oportunidade de se desenvolver tecnicamente nas três vertentes exigidas pelo gênero: a atuação, a dança e o canto; cada uma destas artes tem suas variações estéticas e todas

1 Artigo "As Longas Ondas do Canto Nacional", de Tânia Brandão, publicado na coluna Segunda de Teatro em 31 de julho de 2018. Blog Folias Teatrais - Letras, Cenas, Imagens e Carioquices. Disponível em: http:// foliasteatrais.com.br/sobre/. Acesso em: 18 nov. 2018. precisam estar integradas para que o aluno possa experimentar os diferentes gêneros e estilos musicais.

Os alunos atraídos pelos cursos de teatro musical apresentam muita vontade de aprender como atuar em musicais, porém, estão cheios de dúvidas e medos. Muitos relatam a respeito de suas dificuldades e limitações em atuar cantando, em atuar dançando ou cantando e dançando ao mesmo tempo.

Com base nesta perspectiva, o presente artigo investiga questões que revelam ao aluno-ator uma formação como artista multiperceptivo. A partir da análise das definições que estabelecem um antagonismo entre o artista multiperceptivo e o artista multivirtuoso, proposta por Ernani Maletta (2016) pretende-se compreender o que é ser um artista de musical, bem como desenvolver um trabalho para uma formação qualificada do mesmo. No que tange à questão da percepção, a partir de uma abordagem somática, é importante ressaltar que o teatro proporciona ao público uma experiência sensorial mais intensa, e cabe aos profissionais de teatro, potencializar estes recursos para que o público seja afetado por diferentes canais de percepção.

Nesta pesquisa, busco aflorar cada vez mais, tanto em meus alunos como no meu próprio trabalho de ator, um artista que cante sem, necessariamente, ser um cantor profissional, mas que emocione o público ao cantar; que dance sem ser bailarino, porém que desperte na plateia o desejo de dançar com ele no palco. Todavia, para que isto aconteça, é de suma importância experienciar os fundamentos básicos do canto e da dança de maneira integrada, para que o ator possa desempenhar o seu trabaIho por meio do gesto consciente e multiperceptivo.

\section{O conceito de artista multiperceptivo}

De acordo com o professor e pesquisador mineiro Ernani Maletta (2016) o artista multiperceptivo é aquele "que conseguiu perceber, compreender, incorporar e se apropriar dos conceitos fundamentais que definem e sustentam cada forma de expressão artística" (MALETTA, 2016, p. 24). Maletta esclarece melhor este conceito quan- 
do exemplifica a relação do artista com a habilidade de atuar cantando ou tocando um instrumento:

O artista multiperceptivo, ainda que não chegue a um estágio de virtuosismo técnico como cantor ou instrumentista, pode incorporar os fundamentos da linguagem musical e atuar com sensível musicalidade. Em outras palavras, a habilidade musical do artista não está apenas na sua capacidade em ser um exímio cantor ou instrumentista, mas também na descoberta de possibilidades rítmicas, de variações de intensidade e na apropriação dos parâmetros relacionados ao tempo, indispensáveis para se dizer um texto, para desenhar no espaço um movimento corporal ou para compor a iluminação de uma cena. (MALETTA, 2016, p. 25-26).

Quanto ao trabalho corporal, voltado à expressão corporal ou à dança, Maletta segue a mesma linha de pensamento afirmando que "o ator pode adquirir uma excelente consciência corporal, um efetivo controle dos seus movimentos e realizar com competência elaborados desenhos coreográficos sem, necessariamente, precisar tornar-se um virtuoso bailarino" (MALETTA, 2016, p. 26).

Ernani Maletta destaca outro tipo de artista, o multivirtuoso, que desenvolveu em excelência, as técnicas respectivas às diferentes artes ou, nas palavras do autor, "aquele que desenvolveu as diversas habilidades na sua máxima expressão de virtuosismo" (MALETTA, 2016, p. 24).

$\mathrm{O}$ artista multivirtuoso pode ser compreendido aqui como aquele que domina de tal maneira as técnicas do canto e da dança que o público, muitas vezes, não consegue identificar em qual destas linguagens ele se destaca. Tal fato não é um defeito, porém, o artista pode cair na armadilha de se cristalizar e se engessar nestas mesmas técnicas, a ponto de não emocionar a plateia; corre o risco de se tornar exibicionista, mais preocupado em enaltecer a sua própria imagem do que em revelar o personagem e seus conflitos. A sua figura pode, inclusive, se tornar intimidadora, arrogante e egocêntrica.

A partir de minha experiência em espetáculos musicais e exercendo as mais variadas fun- ções (ator, diretor, coreógrafo e/ou preparador corporal), tenho observado que a relação entre o artista multivirtuoso e a plateia pode, algumas vezes, se tornar mais distanciada e fria. Em contrapartida, a espontaneidade presente no trabalho do artista multiperceptivo apresentado na obra de Maletta pode estabelecer uma relação mais íntima e convidativa do artista com o público, levando o último a embarcar na proposta do espetáculo.

Essa atuação mais fisiológica (das funções do organismo, do funcionamento dos sistemas) está diretamente ligada à história do sujeito, ao seu local de origem e às suas experiências, e está muito próxima, a meu ver, das técnicas de educação somática ${ }^{2}$, as quais tratam da totalidade do ser. Nosso corpo em movimento expressa quem somos e o que pensamos e, por isso, a educação somática pode contribuir para estimular a consciência corporal e o estudo do gesto, revelando assim, o artista multiperceptivo no aluno-ator de teatro musical.

\section{O trabalho com a percepção sensorial}

As questões relativas ao movimento e à percepção dos sentidos, tão presente nos meus espetáculos e na condução do meu trabalho com os atores, passaram a ter mais destaque desde que trabalhei como estagiário no Museu da Vida, o qual pertence à FIOCRUZ. Neste local, fiz parte da equipe do setor denominado Ciência em Cena, entre os anos de 2000 e 2002. A proposta era fundamentada na premissa de que a pesquisa e a experimentação não são exclusividades do mundo científico e estão presentes no processo de ensaio teatral, sendo de suma importância para o desenvolvimento do mesmo, ou seja, o processo artístico e o científico são mais parecidos do que podemos imaginar e caminham lado a lado.

20 termo Educação Somática surgiu pela primeira vez no artigo What is Somatics?, escrito por Thomas Hanna na revista cientifica Somatics, publicada em 1983. Neste artigo, o autor afirmava que Educação Somática é "a arte e a ciência de um processo relacional interno entre a consciência, o biológico e o meio-ambiente. Estes fatores vistos como um todo agindo em sinergia" (HANNA, 1983, p. 7). 
No projeto Ciência em Cena, no qual trabalhei como ator, entre outras funções, nos espetáculos $O$ mensageiro das estrelas $(2000,2001)$ e O mistério do barbeiro ${ }^{3}$ (2002), cada estagiário teria que integrar a equipe de mediadores de uma das demais atividades interativas ao público visitante do museu. Por também possuir experiência em dança ${ }^{4}$, fui selecionado para fazer parte da "Oficina de Percepção dos Sentidos". Nos dois anos em que trabalhei nesta oficina tive a influência direta da pesquisa das mediadoras Jacyan Castilho ${ }^{5}$ e Suzana Herculano-Houzel ${ }^{6}$.

Nessa oficina, que mantém a essência do Museu em sua missão de divulgação científica, apresentamos estímulos que testavam não somente os cinco sentidos humanos, como também dois outros sentidos que não são diretamente estudados nas escolas brasileiras: o equilíbrio e o movimento.

O sentido do movimento está relacionado ao Sistema Proprioceptivo, e a palavra propriocepção origina-se da união da palavra em latim proprius, que significa "próprio" ou "de si mesmo", com a palavra "percepção". De acordo com a pesquisadora brasileira e cirurgiã dentista Narcisa Zeferino da Silva Pavan, que desenvolve estudos sobre os distúrbios temporomandibulares e da coluna cervical envolvendo o sistema proprioceptivo, a maioria dos sentidos são "exteroceptivos", ou seja, fornecem informações externas ao sistema nervoso central (2015).

3 Nesse espetáculo participei ativamente no processo de criação do texto e da concepção do espetáculo, com mais quatro estagiários, sob a direção geral e supervisão de Jacyan Castilho.

4 Integrava a Cia de Dança de Luiz Kleb que mesclava a dança de salão com outros estilos de dança como jazz, contemporâneo, dança de rua e afro.

5 Jacyan Castillho de Oliveira - atriz formada pela Unirio em 1986 e bailarina formada pela Angel Vianna. Concluiu seu mestrado no ano 2000 na Unirio com o título de Arte do Movimento: Uma proposta de abordagem do texto dramatúrgico através da Análise de Movimento Laban.

6 Suzana Herculano-Houzel - neurocientista, pós-doutora pelo Instituto Max Planck na Alemanha (1999), fez doutorado pela Universidade Pierre e Marie Curie na França em 1998, mestrado na Case Western Reserve nos Estados Unidos em 1995 e se formou como bióloga na modalidade genética pela UFRJ em 1992.
Para popularizar estas informações, participei de palestras específicas com a neurocientista Suzana Herculano-Houzel acerca do funcionamento de cada sentido e, no caso do equilíbrio e do movimento, de aulas com Jacyan Castilho, para ministrarmos as Oficinas de Percepção dos Sentidos, incluídas no projeto Ciência em Cena.

As oficinas eram fundamentadas na definição de que, para um sentido ser considerado um sentido humano, é necessário um órgão responsável pela captação das informações sensoriais, que são transmitidas para o cérebro. O cérebro humano não sente, apenas interpreta as informações recebidas pelos órgãos dos sentidos. Os cinco sentidos estudados nas escolas brasileiras se referem aos órgãos externos e são, consequentemente, visíveis: os olhos são os órgãos da visão; a língua é o órgão do paladar; o nariz é o órgão do olfato; os ouvidos são os órgãos da audição e a pele é o órgão do tato (Obs.: Vale ressaltar que este sentido, presente na língua, continua até o estômago e nos permite sentir a textura e a temperatura dos alimentos). Ainda temos o sentido do equilíbrio, cujo órgão está situado nos ouvidos internos, mais precisamente, no labirinto.

No caso, a propriocepção é considerada um sentido interoceptivo que fornece informações conscientes e inconscientes a respeito do interior do organismo, pois os seus órgãos são os músculos e as articulações. Graças à propriocepção os indivíduos aprendem determinados movimentos e podem praticar esportes, dança ou dirigir veículos. Caminhar no escuro sem se desequilibrar é outra tarefa que só é possível pela existência do sentido da propriocepção.

A autora Marilena Chauí tece considerações significativas e exemplifica questões que relacionam a sensação e a percepção. Ela destaca que a sensação e a percepção são as principais formas do conhecimento sensível, também chamado de empírico ou de experiência sensível. Segundo ela, até o século $X X$, a tradição filosófica distinguia sensação de percepção pelo grau de complexidade:

A sensação é o que nos dá as qualidades exteriores e interiores, isto é, as qualida- 
des dos objetos e os efeitos internos dessas qualidades sobre nós. Na sensação vemos, tocamos, sentimos, ouvimos qualidades puras e diretas: cores, odores, sabores, texturas. Sentimos o quente e o frio, o doce e o amargo, o liso e o rugoso, o vermelho e o verde, etc. (CHAUÍ, 1997, p. 120).

Portanto, podemos observar que sentir é algo ambíguo, pois o sensível é, ao mesmo tempo, a "qualidade que está no objeto" e o "sentimento interno" que nosso corpo possui das qualidades sentidas. Por isso, a sensação pode ser compreendida como sendo uma reação corporal imediata a um estímulo ou excitação externa, sem que seja possível distinguir o estímulo exterior e o sentimento interior no ato da sensação. Por isso a autora conclui que: "na realidade, só temos sensações sob a forma de percepções, isto é, de sínteses de sensações" (CHAUí, 1997, p. 120).

A percepção compreende o uso concreto dos sentidos. Em se tratando da percepção relacionada ao teatro, é importante ressaltar aos alunos que esta arte pode proporcionar ao público uma experiência sensorial multiperceptiva, talvez, mais intensa que o cinema, pois vai além da terceira dimensão (3D). O verbo "assistir" no teatro pode significar mais do que apenas ver e ouvir. Precisamos quebrar a resistência imposta pelo teatro ocidental, que separou o público da plateia, pois o espetáculo teatral pode ter cheiro, sabor, ser itinerante e com a participação direta do público, proporcionando uma experiência sinestésica, única e complexa.

O teatro, em sua essência, já nasceu com a possibilidade de afetar o público por meio de vários canais perceptivos e cabe a nós potencializarmos estes recursos. Mas, para que possamos tocar o público e afetá-los por vários canais perceptivos, é de suma importância estimular a percepção sensorial dos próprios alunos atores ao longo das aulas-ensaios.

No início do processo, a sala de aula transforma-se em "sala de percepção" para descobrir / revelar as potencialidades e atributos individuais de cada aluno-ator. A escolha do espetáculo a ser encenado, com a participação da turma, é feita somente a partir desta etapa de preparação e (re)conhecimento dos alunos.

\section{O Curso de Teatro Musical}

Com o compromisso de estar antenada ao mercado de trabalho, a coordenação da Escola Técnica Estadual Henrique Lage (ETEHL), pertencente à Fundação de Apoio à Escola Técnica do Estado do Rio de Janeiro (FAETEC), teve a ideia de implementar um curso de Teatro Musical no ano de 2012. Como professor de teatro no Centro Cultural da ETEHL, situada no bairro de Barreto em Niterói, fui incumbido de elaborar o plano de curso e assumi a sua coordenação no ano de 2013. O curso de Teatro Musical da FAETEC é oferecido aos alunos acima de 14 anos em duas modalidades: a primeira para atender a disciplina de Artes, que integra a grade curricular do ensino médio e, a segunda, extensivo à toda comunidade, através dos Cursos de Formação Inicial e Continuada ou Qualificação Profissional. Ambas as modalidades são oferecidas a cada semestre.

No início do processo, com o foco voltado para o trabalho interdisciplinar, cada professor é incumbido de uma determinada função ou conjunto de funções referentes à sua área de atuação, desenvolvidas ao longo das aulas-ensaio, que acontecem duas vezes por semana. O professor de Teatro é encarregado da escolha do texto e se responsabiliza pela direção geral do espetáculo. Juntamente com os alunos, confecciona a cenografia e o figurino, além de idealizar a iluminação e a maquiagem. Desta forma, o aluno pode experimentar as múltiplas artes que dialogam com o teatro e, com a supervisão do professor, experimenta, na prática o que é ser um artista multiperceptivo. A professora de Dança e/ou Educação Física faz a preparação corporal e auxilia na montagem das coreografias na disciplina que consta na grade curricular com o nome "Corpo". Os professores de Música (dos cursos de piano e violão) são consultados e ajudam na elaboração da trilha sonora e, quando possível, fazem a direção musical dos espetáculos.

Obs: Profissionais de outras disciplinas, não necessariamente artísticas, fazem parte do projeto, por exemplo, uma fonoaudióloga, responsável pela preparação e orientação vocais dos alunos na disciplina chamada "Voz". 


\section{A montagem de espetáculos para conclusão de curso: uma experiência multiperceptiva}

Nos cursos de teatro musical, a integração do canto e da dança com a atuação é um princípio fundamental desse gênero teatral que pode proporcionar ao aluno-ator uma experiência multiperceptiva mais intensa. O Curso de Teatro Musical da FAETEC, oferecido a cada semestre, é concluído com a montagem de um espetáculo, realizado ao final desse período.

A partir de atividades que promovam o autoconhecimento, podemos desenvolver a criatividade do aluno levando o mesmo a expressar a sua identidade cênica. Quando conhecemos as nossas potencialidades e limitações podemos criar deixando a nossa marca, tal qual uma assinatura na construção de um personagem. Quanto às limitações, elas não podem ser vistas como empeciIhos para que possamos desenvolver a nossa arte.

No trabalho com os alunos de teatro procuro desenvolver a consciência de que toda emoção pode ser expressa por meio do gesto. O corpo possui memória sensório-motora, o que pode acionar e/ou despertar as reações físicas que certas emoções nos provocam com os gestos experimentados ao longo dos ensaios. Desta forma, o trabalho poderá acontecer de fora para dentro, como fruto de um treinamento corporal. Como explica Márcia Strazzacappa: "Tudo o que toca o corpo, o coração registra. Tudo o que é falado ao coração, mesmo que em segredo, o corpo escuta" (2012, p. 162).

Quando se trata de Teatro Musical, o maior perigo que surge quando se trabalha a questão do gesto numa cena musical é ilustrar fisicamente tudo o que se canta em uma canção. Não há problema em montar uma coreografia figurativa para uma cena cantada; em muitos casos, ela inclusive auxilia o ator a memorizar a letra da música e potencializa o "cantar com o corpo todo". Porém, precisamos ter cuidado com os excessos. O menos pode ser mais. É preciso estabelecer uma diferença entre o gesto e a ilustração.

Deer e Dal Vera (2013) compreendem o gesto como sendo algo que surge a partir da experi- ência enquanto personagem vivida pelo ator. Já a ilustração é a demonstração de cada imagem ao público e diz muito pouco à atuação contemporânea. Eles definem a ilustração como sendo "a realização de movimentos que não partem do seu personagem, mas ao contrário, servem para representar ou ordenar o assunto sobre o qual o personagem está falando" (DEER; DAL VERA, 2013, p. 303).

Os autores pontuam que a associação literal entre gestos predeterminados e sentimentos é comum em produções extremamente estilizadas ou então, quando se tenta resgatar o espírito deste estilo mais antigo e melodramático de teatro; no entanto, eles reconhecem que todo movimento pode se tornar um gesto justificável, desde que esteja adequado ao contexto e com o comprometimento verdadeiro do ator.

"Tudo que vive no coração ou na cabeça vive também no corpo" (DEER; DAL VERA, 2013, p. 43) - Esta premissa sobre o comportamento humano nos revela que os obstáculos pessoais que conduzem um personagem a tomar diferentes caminhos, ainda que internos, precisam se tornar físicos, para que fiquem claros para o público.

Se você tiver um pensamento ou uma sen-
sação, o seu corpo reagirá: sua respiração
ficará alterada, certos músculos vão se con-
trair ou relaxar e sua postura e seu equilíbrio
se ajustarão. Não existe nada, nem mesmo
um pensamento ou um simples sentimen-
to que não possa ser demonstrado fisica-
mente. (DEER; DAL VERA, 2013, p. 43 ).

Para que isso aconteça, é importante desenvolver um trabalho de treinamento que desperte e sensibilize a voz e o corpo do ator, para que, quando um impulso surgir, ele se sinta capaz de responder com todas as partes de seu corpo. Ao proporcionarmos ao ator experiências físicas de determinado sentimento ou pensamento que se aproximem dos obstáculos reais enfrentados pelo personagem, mais expressiva será a sua atuação, por mais delicados que estes obstáculos se apresentem.

A fim de demonstrar fisicamente o conflito interno do personagem, o professor pode desenvolver 
um trabalho que permita aos alunos-atores conhecer o modo como se relacionam com os próprios sentidos, as relações existentes entre um sentido e os demais e a relação dos sentidos com a enunciação.

Nos casos específicos em que os atores têm pouco tempo disponível ou um personagem com características muito peculiares, eles precisam de um trabalho mais personalizado, com técnicas individualizadas, pois "cada corpo é único" e o "ritmo também é individual". "As técnicas somáticas têm como objetivo resgatar a unidade e a identidade do ser humano. Essas técnicas partiam do princípio de que nenhum ser humano é igual ao outro e de que essas diferenças deveriam ser respeitadas e mantidas" (STRAZZACAPPA, 2012, p. 158).

Durante os ensaios, o professor-diretor precisa construir uma relação de confiança com os alunos-atores, transformando o espaço da sala de aula no lugar propício para que possam explorar todo o seu potencial criativo. A liberdade expressiva do aluno surge à medida que esse se sente seguro no ambiente de trabalho e acolhido pelas pessoas ${ }^{7}$ que se relacionam com ele.

Algumas características do Teatro Musical, por exemplo, contar uma história ou mostrar uma ação por meio da dramatização integrando a música, as canções, os diálogos falados, a atuação e a dança podem justificar sua popularidade e também tornar a aula de teatro mais atrativa para os alunos. No entanto, surge um grande desafio para o professor de teatro que trabalha com este gênero: como desenvolver no aluno-ator múltiplas habilidades artísticas?

Para explorar as relações entre o gesto corporal e a voz, busquei uma prática que pudesse despertar no aluno o artista multiperceptivo. Assim

7 Para lidar com a ansiedade dos demais alunos, o professor precisa conscientizar o grupo da importância de estarem presentes em alguns destes momentos, pois se aprende muito com a experiência do outro. É necessário deixar claro para os alunos, desde o início do trabalho, que todos nós temos virtudes e limitações, inclusive os professores e, por isto, a observação é tão importante para o aprendizado, assim como o aprendizado e o crescimento em conjunto. "Se não há generosidade, não há criação" (STRAZZACAPPA, 2012, p. 167). como nas técnicas somáticas, meu trabalho partiu da intuição e da experimentação. "A teoria e a prática caminham lado a lado e se alimentam mutuamente. A teorização é compreendida como a reflexão profunda e sistemática, alimentada por dados empíricos, intuitivos e científicos posteriores à experimentação." (STRAZZACAPPA, 2012, p. 163).

Ao dizermos um texto, nada deve ser automático, tudo deve ser sentido, por isto, é fundamental desenvolver nos cursos de teatro atividades que proporcionem a integração do corpo à voz e da voz ao corpo de maneira consciente; todo o nosso corpo deve participar desse momento: a voz, a fisionomia, os gestos. Não podemos esquecer que "o ser humano não é a soma de partes, mas um ser inteiro, íntegro, uno" (STRAZZACAPPA, 2012, p. 161).

A prática das atividades que estimulam a percepção dos sentidos pode conduzir os alunos a se depararem com uma série de tensões que costumam ser acionadas em reação a estímulos simples e que podem ser acentuadas durante os exercícios. Por isso, é importante desenvolver atividades que possibilitem a descontração e o equilíbrio de tensões excessivas. A vivência intensa deste processo irá promover um melhor desempenho do ator, além de abrir horizontes criativos por meio da compreensão do funcionamento dos sentidos.

Nos espetáculos musicais, é preciso ressaltar que o ator canta com o corpo em movimento, vivendo, por vezes, situações corpóreas muito diferentes das que acontecem em um show de música tradicional. Ao pesquisar variadas formas de movimentação é muito importante que o conceito de ritmo também seja trabalhado no corpo do ator, para que ele pulse junto com a canção.

Quando o gesto corporal do ator se torna consciente, a sua voz é potencializada, adquirindo mais expressividade, inclusive nos números musicais. É importante ressaltar que a intenção (ideia, pensamento, emoção) expressada pelo corpo em movimento caracteriza o gesto e, consequentemente, toda ação cênica é construída a partir deste mesmo gesto. Graças à percepção do mundo à nossa volta, 
o nosso corpo registra como nos sentimos com relação a tudo que nos afeta. Em sala de aula, esta memória corporal também pode ser desenvolvida com atividades que não só resgatam estas experiências vividas, como também estimulam a nossa percepção sensorial. Por meio destas atividades, os alunos são capazes de reproduzir em cena as reações corpóreas que temos em determinadas situações da vida real.

\section{$O$ aluno como artista multiperceptivo}

Ao longo do processo, muitos alunos se descobrem artistas multiperceptivos e ajudam na elaboração e na produção do espetáculo, confeccionando figurinos e adereços. Outros alunos ajudam na construção dos cenários e na idealização das maquiagens.

No primeiro semestre de 2015, depois de montar alguns espetáculos infantis, direcionei-me para os musicais adultos. Para realizar este desejo recorri ao acervo de filmes musicais internacionais de grande sucesso, pois o acesso aos arranjos instrumentais de suas músicas é, atualmente, facilitado pela internet, assim como o acesso aos filmes dublados ou legendados. Nesta nova fase o primeiro espetáculo encenado foi baseado no musical inglês Walking On Sunshine, lançado no final do ano de 2014, no formato juke-box, reunindo canções de grande sucesso dos anos de 1980. Esse filme não foi exibido nos cinemas brasileiros.

A partir das legendas em inglês e em português e também da dublagem do filme, eu fiz a tradução do texto para a nossa língua e a adaptação teatral da obra, uma vez que a legenda em português não tem um compromisso direto com a linguagem oral. Quanto às músicas, desafiei os alunos a mantê-las em inglês, o que foi recebido por eles com surpresa e entusiasmo. A justificativa para convencê-los a interpretar as canções em seu idioma original partiu do princípio de que tanto a linguagem da música como a linguagem do amor, presentes no espetáculo, são universais. Outro fator decisivo para a escolha em não versionar as canções foi poder observar a tentativa do público de cantar essas canções de grande sucesso, mesmo que em voz baixa, talvez com medo de errar. Nesse sentido, o gesto corporal foi decisivo para auxiliar os alunos a cantarem as histórias presentes em cada uma das músicas e torná-las mais compreensíveis para o público e para eles mesmos. Vale destacar o nível de entrega e de comprometimento de todos os alunos para a realização deste trabalho e a parceria com um dos alunos que, além de ator, é professor formado em Letras - Português / Inglês pela UERJ e ajudou incondicionalmente os seus colegas de turma na pronúncia correta das palavras.

Aqui, abro espaço para reforçar uma particularidade do Curso de Teatro Musical na FAETEC. Como não há pré-requisito para que os alunos se inscrevam no curso procuro sempre respeitar os limites dos alunos na hora da divisão dos personagens para o espetáculo de conclusão de curso. No caso desse aluno, que já exercia a profissão de ator e já havia feito outros cursos de teatro, inclusive Curso de Teatro Musical no CEFTEM $^{8}$, era necessário escolher um personagem que o desafiasse e favorecesse seu crescimento profissional.

Durante o curso, eu costumo aproveitar os momentos iniciais para esclarecer dúvidas específicas dos poucos alunos presentes, o que nem sempre é possível quando a turma está completa. Em toda turma eu procuro identificar se há algum aluno ou aluna que seja bem participativo, dedicado, disciplinado e observador para que possa desempenhar a função de assistente de direção.

O trabalho de conclusão de curso nas turmas do segundo semestre de 2015 e no segundo semestre de 2017 deu continuidade à linha de tradução e

8 O Centro de Estudos e Formação em Teatro Musical - CEFTEM - nasceu da necessidade de existir um espaço que permitisse e estimulasse o diálogo entre o teatro, a dança e o canto, características fundamentais e próprias do gênero. O CEFTEM vem conquistando respeito por ser a $1^{\text {a }}$ escola do gênero fundada no Rio de Janeiro pelo ator e orientador pedagógico Reiner Tenente. Reiner é egresso do Bacharelado em Interpretação Teatral e mestre pelo Programa de Pós-Graduação em Artes Cênicas da UNIRIO. Sua pesquisa na linha de Processos Formativos e Educacionais tem ênfase na formação de atores para o teatro musical. Disponível em: https:// www.facebook.com/Ceftem/. Acesso em: 28 ago. 2018. 
de adaptação de filmes para o teatro. Montamos o musical Fama, o qual fez parte da minha infância. Nesse espetáculo, o desafio foi ainda maior, pois, me propus a fazer a versão das canções incluindo também os alunos nessa fase do trabalho. A participação deles na elaboração das novas letras das músicas foi de suma importância para que compreendessem a importância do envolvimento de todos em cada etapa do processo de criação do espetáculo.

\section{- O professor como artista multiperceptivo}

Ao estimular nos alunos-atores experimentar as múltiplas artes que dialogam com o teatro, o professor também descobre o seu próprio potencial multiperceptivo e percebe que a criatividade é fundamental para ajudar a resolver determinadas questões ao longo do trabalho. Num curso de 20 semanas, por exemplo, o professor não dispõe de tempo suficiente para se dedicar aos problemas, porém precisa direcionar a sua atenção para solucioná-los.

Desde que me tornei professor do curso de Teatro Musical, no primeiro semestre de 2013, assumi também a função de professor de canto. A orientação dos alunos era feita com exercícios específicos para a voz cantada, aprendidos por mim ao longo dos anos em aulas particulares, cantando em corais ou nos musicais em que atuei. $O$ trabalho de despertar a musicalidade nos alunos vai muito além de orientá-los para cantar ou estimulá-los a tocar um instrumento. $\mathrm{O}$ conceito de artista multiperceptivo pressupõe a conscientização dos alunos de que o seu corpo inteiro pode produzir música e dialogar com a canção, com palmas, tapinhas em partes do corpo, estalos de dedos e língua, batendo os pés no chão, entre outros sons.

Minha experiência com os estilos de dança jazz e hip-hop e meu conhecimento avançado em dança de salão e nos fundamentos do balé clássico caracterizam o diferencial do meu trabalho. Vale destacar que a experiência dos alunos com a combinação dos diversos estilos de dança permite que ampliem o leque de possibilidades corporais, fazendo-os adquirir maior consciência do movimento e, consequentemente, tornando o seu gesto mais expressivo.
O professor acumula múltiplas funções também durante as montagens e apresentações dos espetáculos. Além da direção, ele ajuda em todas as etapas da montagem, confeccionando os figurinos e adereços, construindo os cenários, elaborando as maquiagens, idealizando a trilha sonora e organizando a montagem de luz. Venho desenvolvendo esta última desde os tempos em que era aluno da Direção Teatral da UFRJ e, pelo fato de ser ambidestro, possuo a habilidade de operar a luz e o som simultaneamente.

Ainda que participe de todas as etapas do processo de montagem dos espetáculos, evito ao máximo entrar em cena com os alunos, pois, me sinto muito bem representado por eles e posso concentrar minha atenção na direção do espetáculo e no cuidado com as suas atuações, explorando o potencial de cada um. Só entro em cena com os alunos por diversão, em pequenas participações. Quando os alunos-atores reconhecem à dedicação do professor, e o amor que este tem por aquilo que faz, eles se comprometem ainda mais com o trabalho desenvolvido.

\section{Considerações finais}

As atividades artístico-pedagógicas desenvolvidas em sala de aula que integram o gesto corporal à voz proporcionam ao aluno-ator a capacidade de realizar uma cena teatral com mais profundidade e domínio, a qual revelará a identidade cênica de cada um. Por isso, não podemos ignorar o fato de que o trabalho corporal e vocal do ator são os seus principais elementos de comunicação; em outras palavras, são as suas verdadeiras "ferramentas" para uma performance única. Para que a sua identidade cênica se revele, é preciso criar oportunidades para que o aluno-ator experiencie de forma contínua a integração dessas artes nos cursos de teatro musical, a qual Ihe permita realizar uma atuação genuína e plena. Esse é o grande diferencial do Teatro Musical em relação aos demais gêneros, pois, nele, a música, por meio do canto, faz parte da estrutura dramatúrgica tendo o corpo, por meio da dança, como instrumento nesta elaboração. 
Na busca por um artista multiperceptivo, o talento artístico e a identidade cênica dos alunos estão relacionados à sua percepção dos sentidos e à capacidade de expressarem, por meio do gesto consciente, a sua imaginação criadora. Na prática, podemos vivenciar que o teatro musical é, essencialmente, teatro, pois permite ao aluno-ator experimentar, de maneira prazerosa, múltiplas linguagens artísticas em uma única arte, seja na sala de aula ou no palco.

As atividades sensoriais que estimulam a percepção nas aulas-ensaios contribuem para uma formação mais qualificada do ator de musical, no qual a voz precisa ser trabalhada com o corpo em movimento e pulsar com a canção. $O$ ator de musical, ao utilizar a sua experiência sensorial para explorar as múltiplas artes que dialogam com o espetáculo teatral, pode estabelecer uma integração mais consciente entre o canto e a dança para uma atuação mais expressiva. O trabalho de exploração sensorial desenvolvido em sala de aula se aproxima das práticas somáticas e potencializa o artista multiperceptivo no aluno-ator.

Visando a formação de meus alunos, busco construir um trabalho cuidadoso nas aulas, o qual inclui a direção de movimento e a direção do gesto. A pesquisa do gesto corporal pode auxiliar na expressão vocal do ator para revelar as emoções e os pensamentos do personagem na cena musical. A prática na sala de aula cumpre um importante papel neste processo, pois quando transformada em sala de apresentação proporciona ao aluno uma experiência que o prepara para enfrentar os desafios encontrados nas montagens profissionais.

Para que um projeto desta magnitude aconteça, torna-se essencial desenvolver um trabalho coletivo no qual a equipe de professores de teatro, de música e de dança garanta a unidade na atuação do aluno-ator, integrando o gesto corporal à voz no espetáculo musical. O diálogo constante, claro e direto entre os professores e os alunos, é o melhor caminho para que estes possam desenvolver o seu potencial artístico.

Certas atitudes podem desencadear transformações significativas, tanto para os alunos quanto para nós, professores. Quando o professor de teatro se percebe artista em sala de aula, ele cria e produz arte com seus alunos a serviço do bem-estar coletivo, contribuindo, com os seus saberes, para o engrandecimento e a democratização da cultura em seu país. Vale ressaltar que, como educadores, nós professores temos uma missão, um dever a cumprir. Um professor precisa ser mais do que um espectador de si mesmo; ele deve proporcionar a melhor aula que puder. Em salas de aula, professores inventam palcos e cenários, construindo a ponte entre os diversos saberes e seus alunos para que estes possam trilhar seu próprio caminho em busca do conhecimento.

\section{Referências}

BRANDÃO, Tânia. "As Ondas Longas do Canto Nacional". In Coluna Segunda de Teatro, Folias Teatrais - Letras, Cenas, Imagens e Carioquices, 2018. Disponível em: http://foliasteatrais.com.br/coluna-segunda-de-teatro-26/. Acesso em: 18 nov. 2018.

CHAUÍ, Marilena. Convite à filosofia. São Paulo: Editora Ática, 1997.

DEER, Joe; DAL VERA, Rocco. A Atuação em Teatro Musical: curso completo. Tradução. $1^{a}$ Edição, Brasília: Dulcina Editora, 2013.

HANNA, Thomas. "Dictionary Definition of the Word Somatics. Somatics - magazine journal of the mind/ body arts and sciences", New York, Human Kinetics, v. 4, n. $2,19-28,1983$.

MALETTA, Ernani de Castro. Atuação polifônica: princípios e práticas. Belo Horizonte: Editora UFMG, 2016.

PAVAN, Narcisa Zeferino da Silva. Alternativas Tecnológicas na Aplicação de um Estímulo Sensório-Motor sobre o Equilíbrio Postural: estudo retrospectivo. Porto: Universidade Fernando Pessoa, 2015.

STRAZZACAPPA, Márcia. Educação Somática e Artes Cênicas: Princípios e Aplicações. Campinas: Papirus, 2012. 
Recebido: 09/01/2021

Aceito: $18 / 03 / 2021$

Aprovado para publicação: 27/05/2021

Este é um artigo de acesso aberto distribuído sob os termos de uma Licença Creative Commons Atribuição 4.0 Internacional. Disponível em: http://creativecommons.org/licenses/by/4.0.

This is an open-access article distributed under the terms of the Creative Commons Attribution License 4.0 International. Available at: http://creativecommons.org/licenses/by/4.0.

Ce texte en libre accès est placé sous licence Creative Commons Attribution 4.0 International. Disponible sur: http://creativecommons.org/licenses/by/4.0. 